\title{
Pattern of Presentation of Retroperitoneal Hematoma among Sample of Iraqi Patients Attending Surgery Clinic of a Teaching Hospital
}

\author{
Basim Jasim Abdulhussein', Yarub Fadhil Hussein ${ }^{2 *}$, Abdulsalam Hatem Nawar2 \\ ${ }^{1}$ Department of Surgery, AlKaramaha Teaching Hospital, Baghdad, Iraq \\ ${ }^{2}$ Department of Urology, AlKaramaha Teaching Hospital, Baghdad, Iraq \\ Email: ${ }^{*}$ yarubfadhil@gmail.com
}

Received 23 April 2015; accepted 12 May 2015; published 15 May 2015

Copyright (C) 2015 by authors and Scientific Research Publishing Inc.

This work is licensed under the Creative Commons Attribution International License (CC BY).

http://creativecommons.org/licenses/by/4.0/

(c) (i) Open Access

\begin{abstract}
Background: Retroperitoneal heamorrahge is an acute surgical condition that is associated with difficulty of diagnosis, organ injuries and mortality. Materials and Methods: One hundred and two patients with traumatic retroperitoneal hematoma treated in Al Yarmuk teaching hospital from May 2012 to January 2013 were reviewed retrospectively. The data include patient's age, type of injury, presenting symptoms, associated injuries and common site of hematoma. Results: In 102 patients, 69 were males $(67.6 \%)$ and 33 were females $(32.3 \%)$, mean age of 22 years. The comments presenting symptoms was pain $(85.2 \%)$, followed by tenderness $(73.5 \%)$ and shock (58.8\%). Around $38.2 \%$ were injured by blunt trauma and $61.8 \%$ by penetrating trauma. The large bowel was the most common affected organ $26.4 \%$, spleen and kidneys were the second affected organ (23.5\%) while the jejunum and ileum were the third associated organs to be affected (14.7\%). The commonest complication was septicemia, followed by wound infection. The least reported complications were Pulmonary embolism, Fistula, and Intestinal Obstruction. Conclusion: Traumatic retroperitoneal hematoma is life-threatening condition, early diagnosis and correct treatment is of upmost importance.
\end{abstract}

\section{Keywords}

Retroperitoneal, Hematoma, Symptoms, Iraq

\footnotetext{
"Corresponding author.

How to cite this paper: Abdulhussein, B.J., Hussein, Y.F. and Nawar, A.H. (2015) Pattern of Presentation of Retroperitoneal Hematoma among Sample of Iraqi Patients Attending Surgery Clinic of a Teaching Hospital. Surgical Science, 6, $208-213$. http://dx.doi.org/10.4236/ss.2015.65032
} 


\section{Introduction}

Retroperitoneal hemorrhage (or retroperitoneal hematoma) (RPH) refers to an accumulation of blood found in the retroperitoneal space [1]. The retroperitoneum is a large space bounded anteriorly by the posterior parietal peritoneum, posteriorly by the transversalis fascia, and superiorly by the diaphragm. Inferiorly, it extends to the level of the pelvic brim. Few types of RPH have been described in the published reports: Spontaneous, iatrogenic, idiopathic or traumatic hematoma [2]. Idiopathic retroperitoneal hematoma is a rare but potentially life-threatening pathological cause of an acute surgical abdomen. In the early stages, it typically presents as generalized abdominal pain, nausea, anorexia. The symptoms and signs of hypovolemic shock normally present late [3].

Traumatic retroperitoneal hematoma is the common complication of abdominal or pelvic injuries. Retro peritoneum contains a number of visceral and vascular structures in the gastrointestinal, genitourinary, vascular, musculoskeletal and nervous systems [4].

Traumatic retroperitoneal hematoma is reported as high as 18\% - 60\% in English literatures [5].

While the Spontaneous retroperitoneal bleeding is a distinctive clinical entity that can present in the absence of specific underlying pathology or trauma. Isolated case reports exist in the literature stating that spontaneous retroperitoneal haemorrhage may occur without any precipitating factors, such as spontaneous haemorrhage into a pre-existing benign adrenal cyst or bleeding from a left inferior phrenic artery [6].

Haemorrhage within the retroperitoneal area may be massive and may exceed $2000 \mathrm{ml}$ of blood. Experimental data have shown that as much as $4000 \mathrm{ml}$ of fluid can extravasate into the retroperitoneal space under pressure equal to that in the pelvic vessels. The diagnosis of retroperitoneal haematoma is most difficult following blunt trauma to the abdomen and should be suspected in any patient following trauma who had signs and symptoms of haemorrhagic shock but no obvious source of haemorrhage [7].

There is scarcity of data from Iraqi patients, thus we conducted this study with the aim to 1) describe the pattern of presentation of traumatic retroperitoneal hematoma and 2) highlight the problems in the diagnosis of retroperitoneal hematoma.

\section{Patients and Methods}

This is a prospective study of 102 patients with retroperitoneal haematoma carried out at AL-YARMOUK Teaching Hospital, Baghdad, Iraq between the period May 2012 and January 2013, which included all the traumatic injuries admitted to the hospital. A standardized (for the variables under the study) data form was prepared and used for the purpose of collecting data by first hand. The form included: Age, Sex, type of trauma, site of injury on the abdominal wall, signs and symptoms, relevant laboratory tests and radiological study, associated organ injured, postoperative complications and the mortality rate. These data were collected and subjected to statistical analysis and to the results will be shown in the form of figures and tables. The diagnosis of retroperitoneal haematoma was made at laparotomy in the majority of patients since no preoperative radiological facilities were available at night like emergency ultrasound, CT scan and intravenous pyelogram. Many cases were excluded from the study because the patients arrived dead, since no explanatory details concerning their diagnosis could be at hand. The study protocol and investigation were approved by the ethics committee of AlKaramah teaching hospital.

\section{Results}

Of those 102 patients who had RPH, 69 were males (67.6\%) and 33 were females (32.3\%). The peak age was 10 29 yr. (65.6\%), with mean age of 22 years. The comments presenting symptoms was pain (85.2\%), followed by tenderness (73.5\%) and shock (58.8\%).Other symptoms included dyspnea (17.6\%) either due to tear of the diaphragm and herniation of the abdominal viscera to the chest or due to associated chest injury. Haematuria was prevalent among 29 patients (26.4\%) Table 1.

Around $38.2 \%$ were injured by blunt trauma and $61.8 \%$ by penetrating trauma. Among 21 patients (54\%) of those with blunted trauma, the anterior abdominal wall was commonest site of injury. Among the 63 who were inflicted by penetrating injury, the commonest site of the abdomen injured was the anterior abdominal Table 2.

Table 3 shows the percentage of associated organ injuries. It is observable that the large bowel was the most common affected organ $26.4 \%$, spleen and kidneys were the second affected organ (23.5\%) while the jejunum and ileum were the third associated organs to be affected (14.7\%). 
Table 1. Characteristics of the study sample.

\begin{tabular}{|c|c|c|}
\hline Age & No. & $\%$ \\
\hline$<10$ & 12 & 12.5 \\
\hline $10-29$ & 63 & 65.625 \\
\hline $30-49$ & 18 & 18.75 \\
\hline $50+$ & 3 & 3.125 \\
\hline \multicolumn{3}{|l|}{ Sex } \\
\hline Male & 69 & 67.6 \\
\hline Female & 33 & 32.3 \\
\hline \multicolumn{3}{|c|}{ Presenting symptoms } \\
\hline Shock & 60 & 58.8 \\
\hline Haematuria & 29 & 26.4 \\
\hline Tenderness & 75 & 73.5 \\
\hline Pain & 87 & 85.2 \\
\hline Dyspnea & 18 & 17.6 \\
\hline \multicolumn{3}{|l|}{ Cause } \\
\hline Blunt & 39 & 38.2 \\
\hline \multicolumn{3}{|l|}{ Penetrating } \\
\hline Stab & 9 & 8.8 \\
\hline Missile & 54 & 53 \\
\hline
\end{tabular}

Table 2. Common site of injury.

\begin{tabular}{|c|c|c|c|c|}
\hline & Etiology & Site of Trauma & No. & $\%$ \\
\hline \multirow{4}{*}{\multicolumn{2}{|c|}{ Blunt }} & Anterior abd. wall & 21 & 54 \\
\hline & & Posterior abd. wall & 9 & 24.5 \\
\hline & & Flanks & 8 & 21.5 \\
\hline & & Gluteal region & 0 & 0 \\
\hline \multirow{8}{*}{ Penetrating } & \multirow{4}{*}{ Stab } & Anterior abd. wall & 3 & 33.33 \\
\hline & & Posterior abd. wall & 3 & 33.33 \\
\hline & & Flanks & 3 & 33.34 \\
\hline & & Gluteal region & 0 & 0 \\
\hline & \multirow{4}{*}{ Missile } & Anterior abd. wall & 27 & 50 \\
\hline & & Posterior abd. wall & 11 & 20.4 \\
\hline & & Flanks & 7 & 13 \\
\hline & & Gluteal region & 9 & 16.6 \\
\hline
\end{tabular}

Table 4 shows the common anatomical position of hematoma after labrotmy. Midline Supramesocolic and Midline Inframesocolic were entirely a result of penetrating trauma. All other types were more prevalent in penetrating trauma than blunt trauma.

Table 5 depicts the complications caused by the RPH. The commonest complication was septicemia, followed by wound infection. The least reported complications were Pulmonary embolism, Fistula, and Intestinal Obstruction

\section{Discussion}

Traumatic retroperitoneal hematoma is a common, life-threatening complication of abdominal or pelvic injuries, early diagnosis and urgent surgical intervention are of utmost importance [8]. In the current study, we performed 
Table 3. Associated organs injured with R.P.H.

\begin{tabular}{|c|c|c|}
\hline Organs & No. & $\%$ \\
\hline Stomach & 3 & 2.9 \\
\hline Duodenum & 6 & 5.8 \\
\hline Jej. and ileum & 15 & 14.7 \\
\hline Large Bowel & 27 & 26.4 \\
\hline Liver & 18 & 17.6 \\
\hline Spleen & 24 & 23.5 \\
\hline Kidneys & 24 & 23.5 \\
\hline Bladder & 3 & 2.9 \\
\hline Ureters & 3 & 2.9 \\
\hline Mesentery & 9 & 8.8 \\
\hline Aorta & 2 & 1.96 \\
\hline I.V.C. & 5 & 4.9 \\
\hline Lungs & 6 & 5.8 \\
\hline Diaphragm & 3 & 2.9 \\
\hline Vertebrae & 5 & 4.9 \\
\hline Limbs & 33 & 32.3 \\
\hline
\end{tabular}

Table 4. Site of R.P.H. in blunt versus penetrating trauma at laparotomy.

\begin{tabular}{cccccc}
\hline Haematoma & Blunt & \multicolumn{2}{c}{ Penetrating } \\
\hline Midline Supramesocolic & No. & $\%$ & No. & $\%$ \\
Midline Inframesocolic & 0 & 0 & 3 & 100 \\
Lateral perirenal & 0 & 0 & 6 & 100 \\
Paraduodenal & 18 & 40 & 40 & 9 & 60 \\
Pericolonic & 6 & 20 & 24 & 18 & 75 \\
Pelvic & 6 & 25 & 89 & 70.8 \\
Total & 6 & 29.2 & & \\
\hline
\end{tabular}

Table 5. Morbidity Associated with R.P.H.

\begin{tabular}{ccc}
\hline Complications & No. & $\%$ \\
\hline Pulmonary Atelectasis & 3 & 2.9 \\
Pulmonary embolism & 2 & 1.9 \\
Wound Infection & 5 & 4.9 \\
Septicemia & 6 & 5.8 \\
Fistula & 2 & 3.9 \\
Wound dehiscence & 4 & 1.9 \\
Intestinal Obstruction & 2 & 2.9 \\
Paralytic ileus & 3 & \\
\hline
\end{tabular}


a review of 108 cases treated in our institution to help surgeons determine the strategy of diagnosis and treatment for the fatal lesion. In terms of the diagnosis, the signs and symptoms of traumatic retroperitoneal hematoma include abdominal pain, abdominal distension, abdominal mass, severe back, all of which is nonspecific, leading to the difficulties in diagnosing traumatic retroperitoneal hematoma according to clinical features.

CT [9]. The management of retro peritoneal haematoma remains confusing to many surgeons because the available literatures frequently groups patients with blunt and penetrating etiologies together [10]. Because the underlying injuries and their treatment may differ considerably, the nonoperative or operative approach to the common haematomas is based on the mechanism of injury and the haemodynamic status of the patients and extent of associated injuries.

Moreover, retroperitoneal hematoma in different anatomical position has different clinical features and treatment strategy [11]. The retroperitoneal hematoma in centro-medial zone is usually the consequence of the injury of duodenum, pancreas or great vessels. The presence of progressive sign and symptoms, increased amylase in blood and urine, free gas within the abdominal cavity and effusion around duodenum or pancreas indicate the injury of duodenum or pancreas, exploratory laparotomy need to be performed [12]. In the current study, liver injury was confirmed in 18 cases and the repair and drainage were done urgently, all the patients recovered and were discharged. On the other hand, we suggest the stable hematoma without injury of organs in the centromedial zone be managed using conservative approach, but the patients should be monitored closely.

Despite all advances in the fields of technology and surgical techniques, retroperitoneal hematoma resulting from blunt injuries still remains a challenge for the surgeons. The published literature has emphasized to classify RHs into individual zones and traditional surgical management is based on the location of RH and stability of the patient [8]. A CT abdomen is the investigation of choice to evaluate the abdomen in blunt polytrauma victims. Diagnostic peritoneal lavage and focused assessment with sonography for trauma) FAST (are iagnostic tools available for hemodynamically unstable patients [13].

The treatment of retroperitoneal haematoma remains controversial. Whatever the aetiology of the retroperitoneal bleed, all patients should initially be managed in a high dependency unit or intensive care unit with careful monitoring, fluid resuscitation, blood transfusion and normalisation of coagulation factors. In the presence of coagulopathy, inherited clotting disorders, such as congenital haemophilia and acquired (autoimmune) haemophilia, it is generally accepted that clotting factor replacement and a conservative non-intervention approach may suffice [14].

Spontaneous retroperitoneal bleeding is a distinctive clinical entity that can present in the absence of specific underlying pathology or trauma. Isolated case reports exist in the literature stating that spontaneous retroperitoneal haemorrhage may occur without any precipitating factors, such as spontaneous haemorrhage into a pre-existing benign adrenal cyst or bleeding from a left inferior phrenic artery [15]. Spontaneous bleed can occur in patients with factor IX or factor X deficiency, in patients with von Willebrand disease, or in patients with antiphospholipid syndrome. Rarely, spontaneous retroperitoneal haematoma may develop if the patient is on clopidogrel [16].

CT scan is the principal method of diagnosis. It helps in establishing the site, size and likely underlying cause, and should be performed after an aneurysm has been excluded.

The management is by laparotomy and control of hemorrhage from the bleeding point, and when the origin of the bleeding is not found, the prognosis is poor. Our case was treated conservatively after excluding obvious cause by CT scan and angiography.

Although measures were taken to achieve the objectives with optimum precision, the inclusion of patients from a single centre might limit the generalization of the results. Secondly, the deteriorating security conditions in Iraq might limit a timely follow up of the patients.

\section{Conclusion}

Traumatic retroperitoneal hematoma is a life-threatening condition; early diagnosis and correct treatment is of upmost importance.

\section{Acknowledgements}

We would like to thank our patients who were willing to participate in this study. 


\section{Conflicts of Interest}

No financial or other relationships that might lead to a conflict of interest.

\section{References}

[1] Farouque, H.O., Tremmel, J.A., Shabari, F.R., Aggarwal, M., Fearon, W.F., Ng, M.K., et al. (2005) Risk Factors for the Development of Retroperitoneal Hematoma after Percutaneous Coronary Intervention in the Era of Glycoprotein IIb/IIIa Inhibitors and Vascular Closure Devices. Journal of the American College of Cardiology, 45, 363-368. http://dx.doi.org/10.1016/j.jacc.2004.10.042

[2] Selivanov, V., Chi, H.S., Alverdy, J.C., Morris Jr., J.A. and Sheldon, G.F. (1984) Mortality in Retroperitoneal Hematoma. Journal of Trauma and Acute Care Surgery, 24, 1022-1027.

[3] Monib, S., Ritchie, A. and Thabet, E. (2011) Idiopathic Retroperitoneal Hematoma. Journal of Surgical Technique and Case Report, 3, 49-51. http://dx.doi.org/10.4103/2006-8808.78475

[4] Wang, F.B. and Wang, F. (2013) The Diagnosis and Treatment of Traumatic Retroperitoneal Hematoma. Pakistan Journal of Medical Sciences, 29, 573. http://dx.doi.org/10.12669/pjms.292.3168

[5] Sharp, K., Spees, E., Selby, L., Zachary, J. and Ernst, C. (1984) Diagnosis and Management of Retroperitoneal Hematomas after Femoral Vein Cannulation for Hemodialysis. Surgery, 95, 90-95.

[6] Ivascu, F.A., Janczyk, R.J., Bair, H.A., Bendick, P.J. and Howells, G.A. (2005) Spontaneous Retroperitoneal Hemorrhage. The American Journal of Surgery, 189, 345-347. http://dx.doi.org/10.1016/j.amjsurg.2004.11.020

[7] Henao, F. and Aldrete, J. (1985) Retroperitoneal Hematomas of Traumatic Origin. Surgery, Gynecology \& Obstetrics, 161, 106-116.

[8] Hölting, T., Buhr, H., Richter, G., Roeren, T., Friedl, W. and Herfarth, C. (1992) Diagnosis and Treatment of Retroperitoneal Hematoma in Multiple Trauma Patients. Archives of Orthopaedic and Trauma Surgery, 111, 323-326. http://dx.doi.org/10.1007/BF00420059

[9] Murai, Y., Adachi, K., Yoshida, Y., Takei, M. and Teramoto, A. (2010) Retroperitoneal Hematoma as a Serious Complication of Endovascular Aneurysmal Coiling. Journal of Korean Neurosurgical Society, 48, 88-90. http://dx.doi.org/10.3340/jkns.2010.48.1.88

[10] Schulman, S. and Kearon, C. (2005) Definition of Major Bleeding in Clinical Investigations of Antihemostatic Medicinal Products in Non-Surgical Patients. Journal of Thrombosis and Haemostasis, 3, 692-694. http://dx.doi.org/10.1111/j.1538-7836.2005.01204.x

[11] Reid, J.D., Kommareddi, S., Lankerani, M. and Park, M.C. (1980) Chronic Expanding Hematomas: A Clinicopathologic Entity. JAMA, 244, 2441-2442. http://dx.doi.org/10.1001/jama.1980.03310210043026

[12] Federle, M.P., Crass, R.A., Jeffrey, R.B. and Trunkey, D.D. (1982) Computed Tomography in Blunt Abdominal Trauma. Archives of Surgery, 117, 645-650. http://dx.doi.org/10.1001/archsurg.1982.01380290091016

[13] Cardia, G., Loverre, G., Pomarico, N. and Nacchiero, M. (1999) Traumatic Retroperitoneal Lesions. Annali Italiani di Chirurgia, 71, 457-467.

[14] Ylmaz, S., Ören, H., Irken, G., Atabay, B., Duman, M., Ylmaz, E., et al. (2005) Life-Threatening Mediastinal-Retroperitoneal Hemorrhage in a Child with Moderate Hemophilia A and High Inhibitor Titer: Successful Management with Recombinant Activated Factor VII. Journal of Pediatric Hematology/Oncology, 27, 400-402. http://dx.doi.org/10.1097/01.mph.0000174241.03038.b5

[15] Lerer, D.B., Rozenblit, A.M., Cynamon, J., Tubman, G. and Freeman, L.M. (2004) Spontaneous Retroperitoneal Hemorrhage Localized by Blood Pool Scintigraphy. Clinical Nuclear Medicine, 29, 96-98. http://dx.doi.org/10.1097/01.rlu.0000110475.09814.83

[16] Jurisic, D., Doko, M., Glavan, E., Vidovic, D., Matkovic, K. and Pitlovic, V. (2006) Spontaneous Retroperitoneal Haematoma Associated with Clopidogrel Therapy Mimicking Acute Appendicitis. British Journal of Clinical Pharmacology, 62, 248-249. http://dx.doi.org/10.1111/j.1365-2125.2006.02608.x 